\title{
Followers are not followed: observed group interactions modulate subsequent social attention
}

Article

Accepted Version

Capozzi, F., Becchio, C., Willemse, C. and Bayliss, A. P. (2016) Followers are not followed: observed group interactions modulate subsequent social attention. Journal of Experimental Psychology: General, 145 (5). pp. 531-535. ISSN 1939-2222 doi: https://doi.org/10.1037/xge0000167 Available at https://centaur.reading.ac.uk/58446/

It is advisable to refer to the publisher's version if you intend to cite from the work. See Guidance on citing.

To link to this article DOI: http://dx.doi.org/10.1037/xge0000167

Publisher: American Psychological Association

All outputs in CentAUR are protected by Intellectual Property Rights law, including copyright law. Copyright and IPR is retained by the creators or other copyright holders. Terms and conditions for use of this material are defined in the End User Agreement.

www.reading.ac.uk/centaur 
Central Archive at the University of Reading

Reading's research outputs online 
Followers are not followed:

Observed group interactions modulate subsequent social attention

Francesca Capozzi a, Cristina Becchio a,b, Cesco Willemse $\mathrm{c}$, Andrew P. Bayliss* c

a Center for Cognitive Science, Department of Psychology, University of Torino, Torino, Italy

b Robotics, Brain and Cognitive Sciences, Italian Institute of Technology, Genova, Italy

c University of East Anglia, School of Psychology, Norwich, UK

* Corresponding author: Andrew P. Bayliss

Faculty of Social Sciences, School of Psychology, University of East Anglia

Norwich Research Park

Norwich NR4 7TJ

United Kingdom

e-mail: Andrew.P.Bayliss@uea.ac.uk

telephone: +44 (0) 1603597499

Word count: 2997 


\begin{abstract}
We asked whether previous observations of group interactions modulate subsequent social attention episodes. Participants first completed a learning phase with two conditions. In the 'leader' condition one of three identities turned her gaze first, followed by the two other faces. In the 'follower' condition, one of the identities turned her gaze after the two other faces had first shifted their gaze. Thus, participants observed that some individuals were consistently 'leaders' and others 'followers' of others' attention. In the test phase, the faces of 'leaders' and 'followers' were presented in a gaze cueing paradigm. Remarkably, the 'followers' did not elicit gaze cueing. Our data demonstrate that individuals who do not guide group attention in exploring the environment are ineffective social attention directors in later encounters. Thus, the role played in previous group social attention interactions modulates the relative weight assigned to others' gaze: we ignore the gaze of group followers.
\end{abstract}

Keywords: social status, social learning, gaze perception, attention 


\section{Followers are not followed:}

\section{Observed group interactions modulate subsequent social attention}

Humans benefit from the experience of others to gather relevant information about the environment (van Vugt, 2014). Following conspecifics' gaze is one way to make use of social information (Zuberbühler, 2008), hence it is beneficial to shift one's attention to the focus of interest of another person. This "joint attention", has clear importance for social development and throughout life (Moore \& Dunham, 1995). Gaze following can be studied with the gaze cueing paradigm that shows faster responses to objects appearing in gazed-at, relative to other, locations (Driver et al., 1999; Friesen \& Kingstone, 1998). Gaze cueing effects appear to be a reflexive shift of attention, triggered as result of automatic coding of observed gaze direction and engagement of spatial attention systems (Bayliss, Bartlett, Naughtin, \& Kritikos, 2011). Nevertheless, recent work showed that the behavioural history of the gazing face modulate attentional (Dalmaso, Edwards, \& Bayliss, 2015; Frischen \& Tipper, 2006) and affective components of gaze following (Bayliss \& Tipper, 2006; Rogers et al., 2014). It seems that identity-based representations, that utilize the history of social attention interactions with an individual, can influence attention in later encounters. However, it remains unclear whether observing individuals taking different roles in group-based social attention interactions could have consequences for how powerfully their gaze could influence observers' attention in subsequent gaze cueing episodes. If we see an individual repeatedly lead the gaze of other individuals, might their gaze serve as a more powerful cue to our attention than the gaze of an individual previously seen to only follow the gaze of other individuals?

To test this notion, we created a novel two-phase paradigm, in which participants first took part in an adaptation of the gaze cueing paradigm with three faces in each display, where they observed some faces always leading the gaze of others, while other faces always followed gaze (learning phase). Participants then re-encountered these faces in a single-face gaze cueing paradigm (test phase). Our key prediction was that faces previously observed to lead others' attention would be perceived as more effective sources of information about the environment, and thus elicit stronger 
gaze cueing effects compared with faces previously observed to merely follow others' gaze. We also asked participants to rate the faces on two features commonly related to social status, i.e., dominance (Dunbar \& Burgoon, 2005) and attractiveness (Anderson, John, Keltner, \& Kring, 2001). We predicted higher dominance ratings for "leaders" and lower liking ratings for "followers".

\section{Methods}

We report all data exclusions, all experimental manipulations and measures. The study was approved by the School of Psychology Ethics Committee, University of East Anglia.

\section{Participants}

We aimed to collect data from approximately 32 participants based on previous work examining similar questions. To observe cueing effects with $d z \approx .7$ (mean effect sizes in Dalmaso et al., 2015; Dalmaso, Pavan, Castelli, \& Galfano, 2012), $\alpha=.05,1-\beta=.95$, required $n=29$ (G*Power; Faul, Erdfelder, Lang, \& Buchner, 2007).

Thirty-two students participated in return for course credit. All had normal or corrected-tonormal vision, were naïve to the purpose of the study, and gave informed consent. Data from three participants were excluded due to extremely slow RTs ( $>3 S D$ above group mean). The final sample comprised 29 participants (mean age 19.2 years, 28 females). In order to examine overt exploration across conditions, we additionally analysed eyetracking measures and report these in Supplemental $\underline{\text { Material. }}$

\section{Apparatus}

Stimulus presentation and manual reaction time data collection was controlled by E-Prime 2.0 presentation software (Psychology Software Tools, Inc.) on a 23-inch monitor (1920x1080; 59Hz refresh rate), placed $65 \mathrm{~cm}$ from the participant. A Tobii TX300 (Stockholm, Sweden) recorded participants' gaze behaviour (accuracy $0.4^{\circ} ; 120 \mathrm{~Hz}$ ), along with Tobii Studio and Python software. The Tobii I-VT Fixation Filter was applied discarding fixations of durations $<50 \mathrm{~ms}$. 


\section{Learning phase}

We adapted the gaze cueing paradigm in order to include three unfamiliar faces in the scene. As in a classic gaze cueing paradigm, the three faces look to the left or to the right. Critically, the faces did not move simultaneously. We manipulated the sequence of gaze-initiating/gaze-following, such that in the leader condition one identity ( "leader") always moved first, turning toward one direction, followed by the other two faces ("group"). In the follower condition, two faces turned in one direction, and then the third identity ("follower") followed them turning toward the same direction.

Stimuli. The stimuli of the learning phase consisted of 12 faces ( 6 males, 6 females; Poser 9 , Smith Micro Software). For each participant, 1 male and 1 female face served as "leader" identities, and 1 male and 1 female face served as "follower" identities, with the remaining 8 faces comprising the "group". The identities assigned to the leader, follower, or group role were counter-balanced across participants. In each trial, three same-gender faces appeared; the position of each face on the screen was pseudo-randomized across trials, with the only restriction that each "leader" or "follower" identity appeared equally often (16 times) at each of the three positions. Additionally, three objects (a cube, a sphere, and a cylinder) were positioned at the bottom of the screen and randomly varied position across trials. An upright and inverted " $\mathrm{T}$ " served as targets, appearing on one of the lateral objects.

Design \& Procedure. At the beginning of each trial, the three faces were first seen fixating the central object at the bottom of the screen (1500ms) (Figure 1A.1 and A.2). Then, in the leader condition (50\% of trials), one of them ("leader") turned the head toward one of the lateral objects (to the left or to the right) (Figure 1B.1), and the other two ("group") followed after $300 \mathrm{~ms}$ or 600 $\mathrm{ms}$ (50\% of trials each), turning their heads towards the same object (Figure 1C.1). Then, one of the targets appeared either on the left or right object, and thus was either cued (looked at by the faces) or uncued (looked away) (Figure 1D.1). 


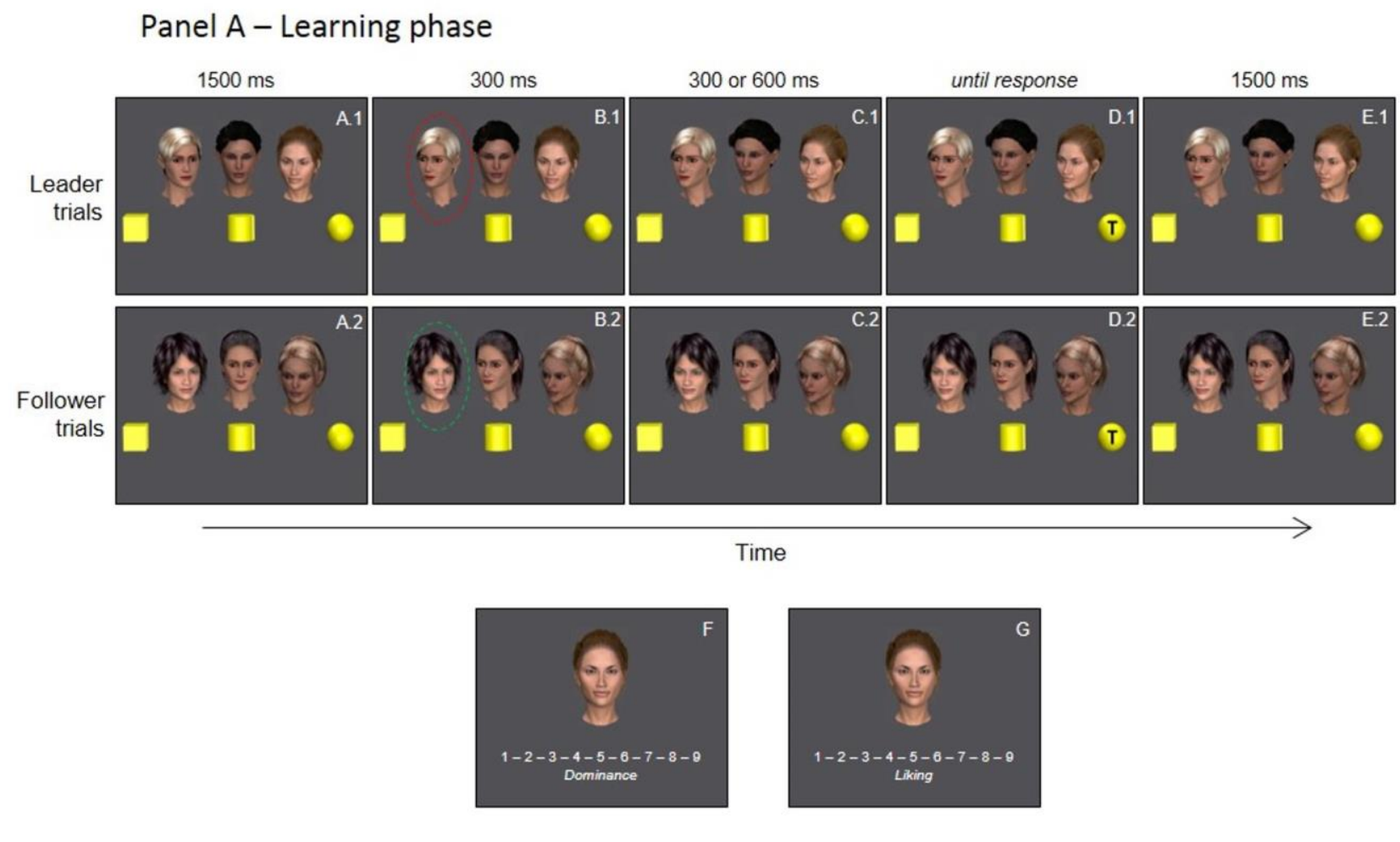

Panel B - Test phase

$600 \mathrm{~ms}$

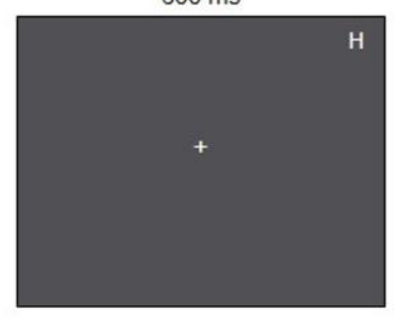

$1500 \mathrm{~ms}$

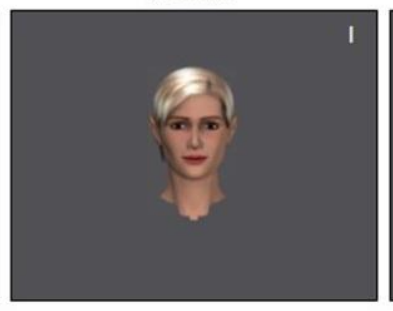

200 or $1000 \mathrm{~ms}$

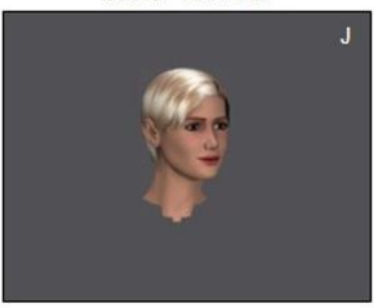

until response

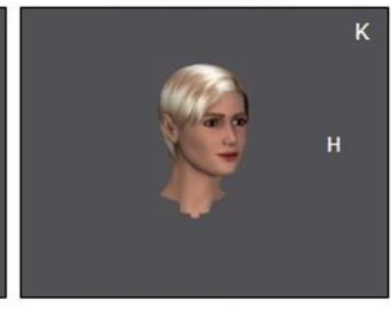

Time 
$500 \mathrm{~ms}$ before the next trial started. A tone sounded upon erroneous responses. In the follower condition (50\% of trials), the difference was that the two faces comprising the group simultaneously first turned their heads, and the remaining identity ("follower") followed after $300 \mathrm{~ms}$ or $600 \mathrm{~ms}$ (50\% of trials each) (see Figure 1). After 16 practice trials in which only targets appeared, the learning phase proceeded over 192 trials split into 3 blocks, over approximately 20 minutes.

\section{Face Ratings}

Next, participants were asked to rate each face on a 1-9 scale for Dominance ("How much you perceive them as dominant personalities") and Liking ("How much you like them") (see Figure 1). The 12 faces were presented alone in a random order. Participants were required to rate each face on the screen for one scale and after for the other. Whether they started from Dominance or from Liking was counterbalanced across participants. Participants were asked to select a number from 1 to 9 and press the corresponding key on the keyboard, so that higher scores were given to the faces perceived as more dominant or liked more, respectively.

\section{Test phase}

After a 5-minute break, participants performed the test phase.

Stimuli. In this phase, only the two identities that had served as 'leaders' and the two identities that had served as 'followers' in the learning phases were used as gaze cuers in a standard gaze cueing paradigm (see Figure 1). The letters " $\mathrm{H}$ " and "N" were targets.

Design \& Procedure. At the beginning of each trial, a fixation cross was replaced after $600 \mathrm{~ms}$ by one of the identities looking at the participant for 1500ms (Figure $1 \mathrm{H}$ and $1 \mathrm{I}$ ). Then, the head turned toward the left or the right for $200 \mathrm{~ms}$ or $1000 \mathrm{~ms}$ (50\% trials each) (Figure 1J), when a target appeared in the cued or uncued direction (Figure 1K). Participants were asked to ignore the gaze shift of the face and identify the target letter as quickly and accurately as possible. Participants were required to press one of two adjacent coloured (yellow and blue) keys on a keyboard using their index and middle fingers, depending on whether the target was an $\mathrm{H}$ or an $\mathrm{N}$ (key-target assignment was counterbalanced across participants). A tone sounded upon erroneous responses. After a 400ms 
blank interval the next trial started. After sixteen practice trials, in which only the targets appeared, participants completed the test phase as described above. The test phase comprised 256 trials split over four blocks and took approximately 25 minutes.

\section{Results}

\section{Learning phase}

Two separate repeated measures ANOVA were conducted on accuracy (percent) and reaction times $(\mathrm{ms})$ to targets, with leadership (2: leader, follower $) \times$ cueing $(2$ : cued, uncued $) \times$ SOA $(2$ : $300 \mathrm{~ms}, 600 \mathrm{~ms}$ ) as within-subject factors.

Overall accuracy was $97.2 \%$. The accuracy ANOVA yielded a main effect of cueing, $F(1,28)=8.708, p=.006, \eta^{2} p=.237$, with higher accuracy in cued trials $(M=97.9)$ than in uncued trials $(M=96.5)$, and a main effect of SOA, $F(1,28)=10.343, p=.003, \eta^{2}{ }^{2}=.270$, with higher accuracy at the $600 \mathrm{~ms}$ SOA $(M=97.8)$ than at the 300ms SOA $(M=96.5)$. No other significant effects were observed ( $p$ s>.250). The mean percentages of accuracy in leader and follower conditions were 97.06 and 97.31, respectively $(p=.562)$.

Correct responses contributed to the mean reaction times for each participants in each condition. There was a significant main effect of cueing, $F(1,28)=68.427, p<.001, \eta^{2}{ }_{p}=.710$, due to faster reaction times in cued $(578 \mathrm{~ms})$ than uncued $(646 \mathrm{~ms})$ trials (i.e., a $68 \mathrm{~ms}$ cueing effect, $95 \%$ CI[51,85]). The interaction between leadership and cueing was not significant, $F(1,28)=.907, p>.250, \eta^{2}=.031$, suggesting that the cueing procedure was unaffected by the leadership manipulation during this learning phase. The main effect of leadership was significant, $F(1,28)=7.590, p=.010, \eta^{2}=.213$, due to slightly slower reaction times in leader trials $(617 \mathrm{~ms})$ compared with follower trials (606ms). The main effect of SOA was also significant, $F(1,28)=16.545, p<001, \eta^{2}{ }_{p}=.371$, with slower reaction times at $300 \mathrm{~ms}$ SOA $(622 \mathrm{~ms})$ than the $600 \mathrm{~ms}$ SOA (601ms). No other effects were significant, $F<1.232, p>.250$.

Finally, in general terms, the eyetracking data did not yield informative effects across leadership conditions. However, we found that participants looked longer at whichever component 
of the scene moved their eyes last. Moreover, faces were looked at for longer at the end of cued trials compared with uncued trials (full description in Supplemental Material).

\section{Face Ratings}

Two separate repeated measures ANOVAs, with type of identity (3: leader, follower, group) as within-subjects factors were performed for Dominance and Liking ratings. The analyses did not reveal significant effects, $F s(1,28)<2.166, p s>.130$ (see also Supplemental Material).

\section{Test phase}

ANOVAs were conducted on accuracy $(\mathrm{M}=96.2 \%)$ and reaction times to targets, with leadership (2: leader, follower $) \times$ cueing $(2$ : cued, uncued $) \times \operatorname{SOA}(2: 200 \mathrm{~ms}, 1000 \mathrm{~ms})$ as withinsubject factors. The accuracy ANOVA yielded no significant effects, with similar accuracy in the leader $(96.0 \%)$ and follower $(96.3 \%)$ conditions, $F<1, p=.577$. Cueing was also non-significant (cued: $\mathrm{M}=96.4 \%$; uncued: $\mathrm{M}=95.9 \%), F(1,28)=3.403, p=.076$.

Correct mean reaction times for each participant in each condition (see Figure 2). The ANOVA on reaction times yielded a main effect of cueing, $F(1,28)=7.958, p=.009, \eta^{2} p=.221$, due to faster reaction times in cued $(581 \mathrm{~ms})$ than uncued $(595 \mathrm{~ms})$ trials $(14 \mathrm{~ms}$ cueing effect, $C I[4,25])$. This effect was moderated by the interaction between leadership and cueing, $F(1,28)=4.936, p=.035, \eta^{2} p$ $=.150$. Follow-up $t$-tests exploring this interaction revealed that identities who had previously acted as gaze leaders produced reliable gaze cueing (22 ms cueing effect, $C I[11,32])$, $t(28)=4.097, p<.001, d z=.761$. In contrast, identities who had previously acted as followers produced no reliable gaze cueing (6ms cueing effect, $C I[-7,20]), \mathrm{t}(28)=.960, p>.250, d z=.177$. Moreover, whereas cueing was significant at both SOAs for leaders (200ms SOA: $22 \mathrm{~ms}$ cueing effect, $t(28)=-$ $3.43, p=.002, d z=.91 ; 1000 \mathrm{~ms}$ SOA: $21 \mathrm{~ms}$ cueing effect, $t(28)=-2.81, p=.009, d z=.52$, it did not approach significance at either SOA for followers (3ms cueing effect at the 200ms SOA, $p>.250, d z=.055,10 \mathrm{~ms}$ cueing effect at the $1000 \mathrm{~ms} \mathrm{SOA}, p=.221, d z=0.23)$. A Bayes analysis supported the null effect of gaze cueing by followers with reasonable evidence $(B=0.35)$, albeit falling short of the conventional criterion for substantial evidence for the null ( $\mathrm{B}=0.33$; Dienes, 
2014). This was based on a uniform distribution varying 10-32 (lower/upper CIs of the mean effect in the leader condition).

The ANOVA also revealed a main effect of SOA, $F(1,28)=30.267, \mathrm{p}<.001, \eta^{2}{ }_{p}=.519$, with slower reaction times with shorter SOA (200ms SOA: 598ms; 1000ms SOA: 578ms). No other effects were significant, $F<1, p>.250$ ).

Eyetracking data did not reveal any significant effect related to the leadership manipulation, but there were longer dwell times on faces in the 200 than the $1000 \mathrm{~ms}$ SOA during target presentation.

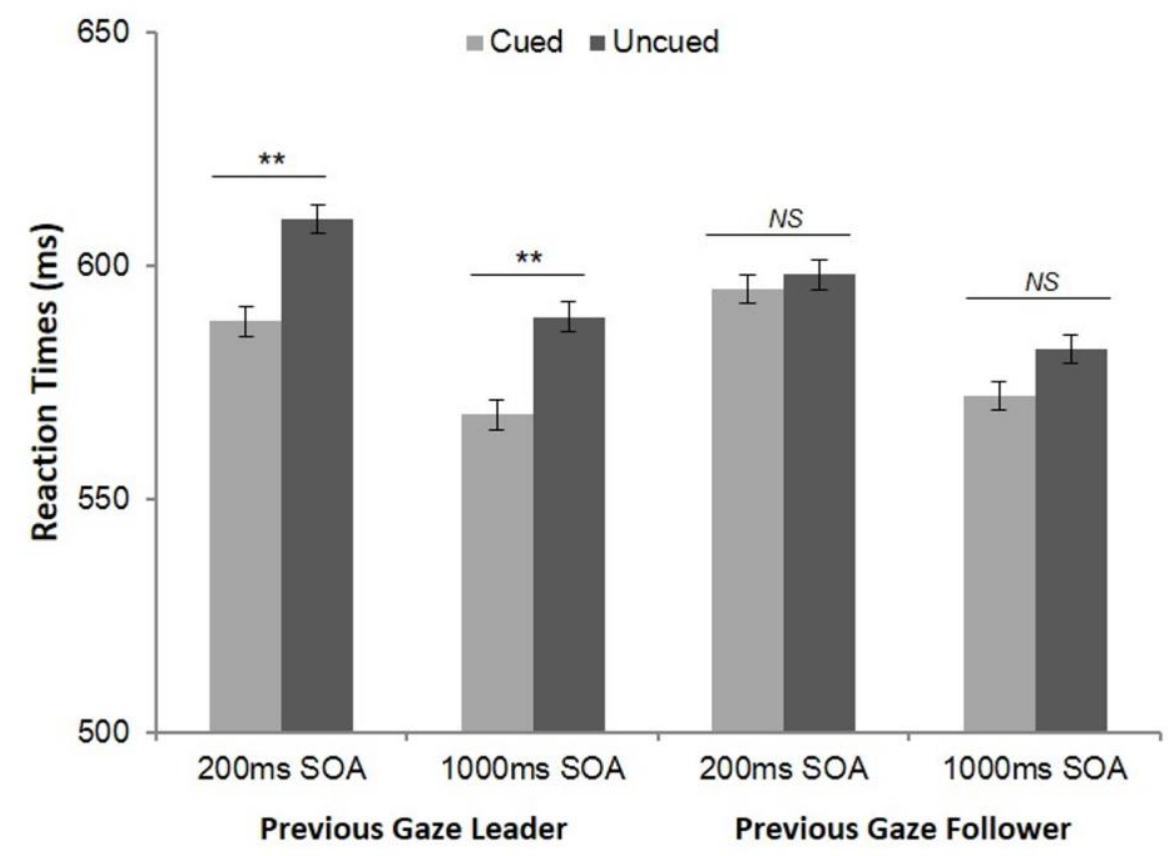

Figure 2. Mean reaction times (RTs) of cued and uncued trials in the leader and the follower conditions of the test phase, at each SOA; error bars represent SEM for within-subjects designs (Loftus \& Masson, 1994; leadership $\times$ cueing $\times$ SOA interaction term $)(* * p<.01)$.

\section{General Discussion}

The social attention system appears to operate principally through robust perceptual processing of visual social cues (Bayliss et al., 2011; Edwards, Stephenson, Dalmaso, \& Bayliss, 2015). Our results demonstrate that the extent to which these cues are effective at influencing 
attention can depend on the behavioural history of the identities producing those cues, showing that person information derived from vicariously observed social orienting episodes modulates these supposedly low-level social orienting mechanisms. Specifically, in comparison to 'gaze leaders', individuals who have been previously observed following others' gaze are apparently powerless to influence observer's visual attention in subsequent encounters. This suggests that the role played in previous group interactions informed participants on the degree of power that some individuals had relative to the group. This information was then applied to subsequent encounters and, as result of this social coding of individuals' gaze (Joyce, Schenke, Bayliss, \& Bach, 2015), modulated participants' use of social information in respect to the perception of the environment. The present results also concord with recent work on the role of social status (the position within a social hierarchy; Koski, Xie, \& Olson, 2015) in modulating social attention, with individuals ascribed higher status causing stronger gaze cueing than those ascribed low-status (Dalmaso et al., 2012).

Although we predicted that gaze cueing would be modulated by the observed history of social attention, our a priori expectation was to observe an increase in salience of gaze cues from the 'leaders' of others' attention. Instead, the leaders showed reliable, yet typical, gaze cueing, while 'followers' were ineffective gaze cuers: a suppression for followers, rather than a boost for leaders. Because each face served as leader and follower for different participants, and all faces produced valid cues to target location on only half of trials, both the physical appearance and the consistency of information provision can be discounted as factors of this differential effect. One could argue that observers might learn about leaders in the learning phase simply because they moved first.

However, this does not explain why the followers gaze cueing was suppressed, and would also predict differences during the learning phase, which we did not observe. Therefore, what seems to be driving the effect is the observed difference in the roles each face took in previous encounters some were leaders that others had followed, whereas others merely followed.

These findings are striking as they suggest that we are equipped with fast and undemanding $\underline{\text { mechanisms that allow us grasp and use information about social power. We demonstrated this via a }}$ 
vicariously evocation of "leadership", based on the exhibited ability to explore the environment (Krause, Hoare, Krause, Hemelrijk, \& Rubestein, 2000), rather than by manipulating physical appearance (Ohlsen, van Zoest, \& van Vugt, 2013) or explicit information about individuals (Dalmaso et al. 2012). Individuals who show independence in exploring the environment, thus leading others' attention, are later gaze-cued as reliable source of information. On the contrary, individuals who follow others' attention are later non-followed.

Social animals follow leaders in order to gain resources: leaders are the first to "move", and by following them, the group enhances survival probability for all individuals (Couzin, Krause, Franks, \& Levin, 2005). In humans, implicit information about status can influence social attention; under conditions of perceived threat, dominant-looking faces elicit stronger gaze cueing than nondominant faces (Ohlsen et al., 2013). An inverse relationship may hold for people perceived as followers: they are not perceived as individuals able to point out valuable resources, thus their gaze can be ignored (for discussion, Van Vugt, Hogan, \& Kaiser, 2008). This, we suggest, points to the effects that social influence, rather than facial dominance, can have on preferential gaze-cueing (for discussion, Anderson \& Berdahl, 2002). We note that exploring prestige, distinct from dominance, may be useful for future research (Cheng, Tracy, Foulsham, Kingstone, \& Henrich, 2013). Moreover, it is likely that these effects are sensitive to modulation by contextual variables, for example the gender of either party (e.g. Bayliss, di Pellegrino, \& Tipper, 2005; Ohlsen et al., 2013).

To conclude, our results speak to the critical role that group interactions have in our representation of others. The behaviour of an individual relative to the group informs us about her social influence, and this information is retained in later interactions. Critically, this exerts an impact on the way in which we explore the environment on the base of social information: we do not follow the gaze of people who follow the crowd. 


\section{Acknowledgments}

The authors would like to thank Andre Bester, University of East Anglia, for assistance with programming.

\section{Funding}

This work was supported by a University of Turin post-graduate studentship to F. Capozzi, a University of East Anglia post-graduate studentship to C. Willemse. 


\section{References}

Anderson, C., \& Berdahl, J. L. (2002). The experience of power: examining the effects of power on approach and inhibition tendencies. Journal of Personality and Social Psychology, 83(6), 1362-1377. http://doi.org/10.1037/0022-3514.83.6.1362

Anderson, C., John, O. P., Keltner, D., \& Kring, A. M. (2001). Who attains social status? Effects of personality and physical attractiveness in social groups. Journal of Personality and Social Psychology, 81(1), 116-132. http://doi.org/10.1037/0022-3514.81.1.116

Bayliss, A. P., Bartlett, J., Naughtin, C. K., \& Kritikos, A. (2011). A direct link between gaze perception and social attention. Journal of Experimental Psychology: Human Perception and Performance, 37(3), 634-644. http://doi.org/10.1037/a0020559

Bayliss, A. P., Pellegrino, G. D., \& Tipper, S. P. (2005). Sex differences in eye gaze and symbolic cueing of attention. Quarterly Journal of Experimental Psychology, 58A(4), 631-650.

Bayliss, A. P., \& Tipper, S. P. (2006). Predictive gaze cues and personality judgments: Should I trust you? Psychological Science, 17(6), 514-520. http://doi.org/10.1111/j.14679280.2006.01737.x

Cheng, J. T., Tracy, J. L., Foulsham, T., Kingstone, A., \& Henrich, J. (2013). Two ways to the top: $\underline{\text { Evidence that dominance and prestige are distinct yet viable avenues to social rank and }}$ influence. Journal of Personality and Social Psychology, 104(1), 103-125.

Couzin, I. D., Krause, J., Franks, N. R., \& Levin, S. A. (2005). Effective leadership and decisionmaking in animal groups on the move. Nature, 433(7025), 513-516. http://doi.org/10.1038/nature03236

Dalmaso, M., Edwards, S. G., \& Bayliss, A. P. (2015). Re-Encountering individuals who previously engaged in joint gaze modulates subsequent gaze cueing. Journal of Experimental Psychology : Learning, Memory, and Cognition. http://doi.org/http://dx.doi.org/10.1037/xlm0000159

Dalmaso, M., Pavan, G., Castelli, L., \& Galfano, G. (2012). Social status gates social attention in 
humans. Biology Letters, 8(3), 450-452. http://doi.org/10.1098/rsbl.2011.0881

Dienes, Z. (2014). Using Bayes to get the most out of non-significant results. Frontiers in Psycholology, 5: 781. doi: 10.3389/fpsyg.2014.00781

Driver, J., Davis, G., Ricciardelli, P., Kidd, P., Maxwell, E., \& Baron-Cohen, S. (1999). Gaze perception triggers reflexive visuospatial orienting. Visual Cognition, 6(5), 509-540. http://doi.org/10.1080/135062899394920

Dunbar, N. E., \& Burgoon, J. K. (2005). Perceptions of power and interactional dominance in interpersonal relationships. Journal of Social and Personal Relationships, 22(2), 207-233. http://doi.org/10.1177/0265407505050944

Edwards, S. G., Stephenson, L. J., Dalmaso, M., \& Bayliss, A. P. (2015). Social orienting in gaze leading: A mechanism for shared attention. Proceedings of the Royal Society B: Biological Sciences, 282, 20151141. http://doi.org/http://dx.doi.org/10.1098/rspb.2015.1141

Faul, F., Erdfelder, E., Lang, A.-G., \&Buchner, A. (2007). G*Power 3: A flexible statistical power analysis program for the social, behavioral, and biomedical sciences. Behavior Research Methods, 39(2), 175-191. http://doi.org/10.3758/BF03193146

Friesen, C. K., \& Kingstone, A. (1998). The eyes have it! Reflexive orienting is triggered by nonpredictive gaze. Psychonomic Bulletin \& Review, 5(3), 490-495. http://doi.org/10.3758/BF03208827

Frischen, A., \& Tipper, S. P. (2006). Long-term gaze cueing effects: Evidence for retrieval of prior attentional states from memory. Visual Cognition, 14(3), 351-364. http://doi.org/10.1167/5.8.409

Joyce, K., Schenke, K., Bayliss, A. P., \& Bach, P. (2015). Looking ahead: Anticipatory cueing of attention to objects others will look at. Cognitive Neuroscience. http://doi.org/10.1080/17588928.2015.1053443

Koski, J. E., Xie, H., \& Olson, I. R. (2015). Understanding social hierarchies: The neural and psychological foundations of status perception. Social Neuroscience, 10(5), 527-550. 
http://doi.org/10.1080/17470919.2015.1013223

Krause, J., Hoare, D., Krause, S., Hemelrijk, C. K., \& Rubenstein, D. I. (2000). Leadership in fish shoals. Fish and Fisheries, 1(1), 82-89.

Loftus, G. R., Masson, M. E. J (1994). Using confidence intervals in wihin-subject designs. Psychonomic Bulletin \& Review, 1(4), 476-490.

Moore, C., \& Dunham, P. J. (Eds.) (1995). Joint attention: Its origins and role in development. Hove, UK: Lawrence Erlbaum.

Ohlsen, G., van Zoest, W., \& van Vugt, M. (2013). Gender and facial dominance in gaze cuing: Emotional context matters in the eyes that we follow. PLoS ONE, 8(4), e59471. http://doi.org/10.1371/journal.pone.0059471

Rogers, R. D., Bayliss, A. P., Szepietowska, A., Dale, L., Reeder, L., Pizzamiglio, G., ... Tipper, S. P. (2014). I want to help you, but I am not sure why: Gaze-cuing induces altruistic giving. Journal of Experimental Psychology. General, 143(2), 763-77. http://doi.org/10.1037/a0033677

van Vugt, M. (2014). On Faces, Gazes, Votes, and Followers: Evolutionary Psychological and Social Neuroscience Approaches to Leadership. In J. Decety \& Y. Christen (Eds.), New Frontiers in Social Neuroscience (pp. 93-110). Heidelberg: Springer. (IPSEN foundation). van Vugt, M., Hogan, R., \& Kaiser, R. B. (2008). Leadership, followership, and evolution: some lessons from the past. The American Psychologist, 63(3), 182-196. http://doi.org/10.1037/0003-066X.63.3.182 Zuberbühler, K. (2008). Gaze following. Current Biology, 18(11), R453-R455. http://doi.org/doi:10.1016/j.cub.2008.03.015 